\title{
Adoção internacional no ordenamento jurídico brasileiro: um exame sob o prisma do princípio constitucional da dignidade da pessoa humana
}

\author{
João Carlos Leal Júnior ${ }^{1}$ \\ Natália Taves Pires ${ }^{2}$
}

\begin{abstract}
Resumo
Objetiva, aprioristicamente, dissertar sobre 0 instituto da adoção e sua proeminência no interior da sociedade, notadamente como forma de mitigar 0 número de crianças e adolescentes que se encontram relegados ao abandono em instituições de caridade, seja por serem órfãos, ou mesmo porque indesejados por seus genitores, ficando privadas de convivência familiar. Analisa-se tal tema à luz do princípio constitucional da dignidade da pessoa humana, pedra angular do ordenamento jurídico brasileiro. Deságua, finalmente, em sede internacional, questão principal a ser enfrentada, ponderando-se quanto às conveniências e desvantagens advindas de tal modalidade.
\end{abstract}

Palavras-Chave: Adoção; Adoção Internacional; Adolescente; Criança; Dignidade da Pessoa Humana; Estatuto da Criança e do Adolescente.

\section{Introdução}

O estudo da temática em comento apresenta-se de extrema relevância em razão de sua importância para o Direito de Família, posto que o instituto da adoção propicia para infindas crianças e adolescentes abandonados a possibilidade de integrar uma unidade familiar. De se salientar que, conquanto ser matéria versada pelo novel Código Civil brasileiro, sua preeminência extrapola a seara do Direito Privado, eis que diz respeito à participação efetiva do Estado no sentido de fiscalizar seu processamento bem como de salvaguardar os direitos das crianças e adolescentes, seja através do Poder Judiciário, seja pela atividade do Ministério Público, ou ainda pelo Poder Executivo, na esteira do que preleciona nossa Constituição.

0 instituto em epígrafe é hodiernamente visto como algo intimamente veiculado ao sentimento ético e religioso de caridade, haja vista que oportuniza a uma criança

\footnotetext{
${ }^{1}$ Discente de Direito e pesquisador da Universidade Estadual de Londrina - PR; estagiário do Ministério Público-PR

${ }^{2}$ Advogada; mestra em direito pela Universidade Eurípides Soares da Rocha - SP; orientadora do núcleo de prática do Centro Universitário Salesiano de Araçatuba - SP.
} 
abandonada pertencer a um núcleo familiar, suprindo as deficiências familiares tidas até 0 momento de sua adoção.

Nossa Carta Magna, tão enaltecida pela consagração dos direitos fundamentais trazida em seu cerne, por diversas ocasiões não atinge o que o apregoa, como, exempli gratia, o amparo à infância previsto no caput de seu artigo 6ㅇ. ao tratar dos direitos sociais, ou o dever conjunto da sociedade e do Estado assegurar à criança e ao adolescente o direito à vida, à saúde, à alimentação, à dignidade, ao respeito e à convivência familiar. Chega a professar na parte final do artigo 227 ser dever estatal "colocá-los a salvo de toda a forma de negligência, discriminação, exploração, violência, crueldade e opressão".

Uma análise mais profunda sobre o assunto, tendo em mente a situação atual das crianças desamparadas, é capaz de fazer-se refletir sobre a necessidade de incentivar a adoção, buscando a aplicação do que preceitua a Declaração Universal de Direitos Humanos quando assevera que a infância tem direito a cuidados e assistência especiais, o que é incoerente com a circunstância de haver infantes relegados em instituições de caridade.

Por derradeiro, pretende-se a incursão no âmbito do Direito Internacional ao ponderar acerca da adoção por pais estrangeiros, sem domicílio ou residência no Brasil, tema que desperta os mais variados debates. Questionam-se as conveniências e desvantagens inerentes ao instituto sub examine à luz da Convenção de Haia sobre Adoção Internacional e das regras estatuídas no Estatuto da Criança e do Adolescente, assim como no Código Civil.

\section{A condição do menor abandonado no Brasil}

As crianças e adolescentes que não vivem em companhia de seus genitores por estarem abrigadas em instituições passam a ser vítimas da situação em que se encontram, posto que em grande parte dos abrigos existentes não se constata empenho no sentido de resguardar os vínculos familiares dos infantes ou de tentar uma volta desses às famílias de origem, nos casos em que tal fato seria possível, além de ser difícil a existência de condições dignas no que diz respeito à permanência dos internos nos abrigos.

É sabido que em nossa sociedade não há o preparo necessário para proporcionar uma família substituta para os menores que não podem mais conviver com sua família 
biológica, especialmente em razão do grande preconceito existente com relação ao núcleo familiar adotivo, situação essa que urge ser modificada.

É extremamente imperiosa, para o incremento social, a intervenção racional da sociedade em seu próprio processo de desenvolvimento, nos planos de organização comunitária, através de ação voluntária ou da integração de empreendimentos públicos e privados, de forma que se proteja as famílias mais necessitadas, e incentive-se a adoção de crianças abandonadas.

Consoante doutrina Lídia Weber (1995), para lidar com os dramáticos problemas das crianças existem inúmeras frentes de ação, as quais devem sempre ser interdisciplinares e com parcerias. Não se deve culpar um ou outro segmento social, mesmo porque nenhuma ação isolada surte efeitos, mas sempre interligada com outras obras e eventos. Uma frente de trabalho idônea a "devolver a dignidade e o respeito dos internos que já estão abandonados, e proporcionar-Ihes o direito primário de 'convivência familiar e comunitária' é a adoção".

Há perspectiva de um gravame nas manifestações anti-sociais se medidas efetivas não forem tomadas. 0 momento, portanto, urge por atitudes reais em benefício das crianças carentes.

A Lei $8.069 / 90^{3}$ veio dar maior possibilidade aos menores de integrarem uma nova família, quando, em seu artigo 42, viabilizou, inclusive, a adoção por pessoas solteiras. Prescreve 0 artigo em destaque que "podem adotar os maiores de vinte e um anos, independentemente de estado civil". Nessa esteira, consoante o escólio do professor José Sebastião de Oliveira (2002), uma pessoa, por opção própria, pode perfeitamente adotar uma criança ou adolescente como seu filho, constituindo a chamada família monoparental.

Despiciendo, dessarte, o estado civil do adotante, eis que é possível que esse proporcione um lar equilibrado e digno àquela criança que jamais teve segurança no seio familiar, se é que algum dia chegou a ter uma família, já que há infantes que são abandonados em tenra idade crescendo, desde então, em orfanatos, sem saber sequer sua origem, situação essa lastimável.

De se enfatizar o fato de existir inúmeros casais estrangeiros que desejam ter um filho, sendo, desta feita, essencial que as burocracias sejam minimizadas, permitindo, em

\footnotetext{
${ }^{3}$ Dispõe sobre o Estatuto da Criança e do Adolescente e dá outras providências.
} 
maior escala, a adoção internacional. Não se trata de abrir mão das prescrições acautelatórias em favor da criança a ser adotada por pais estrangeiros, mas sim, de mitigar entraves existentes nessa seara.

\section{Considerações acerca da família substituta}

Segundo a dicção do artigo $19^{4}$ do Estatuto da Criança e do Adolescente, deve ser conferida prioridade à família natural, pois todo infante deverá ser criado e educado no cerne de sua família biológica. Extraordinariamente será criado dentro de família substituta. A Lei pretende priorizar a família natural, com a permanência da criança em seu interior, por ser preferencial a convivência com aquela, tendo em vista os laços familiares existentes em decorrência do nascimento.

Entretanto, e infelizmente, sabe-se que um sem número de crianças nasce no bojo de famílias desestruturadas, seja porque os pais partiram para a criminalidade, seja porque não têm o preparo para educar um filho, ou ainda porque não desejavam seu nascimento, fazendo com que 0 entreguem a abrigos destinados a cuidar de menores abandonados. Nessas circunstâncias, deve-se lançar mão do instituto da família substituta, pois toda criança merece pertencer a uma entidade familiar, na linha do que preconiza o ventilado artigo 19 da Lei 8.069/90.

Independentemente da situação jurídica da criança, seja ela adotada ou tutelada, verbi gratia, a família substituta passa a desempenhar as funções da família original, devendo representar para o infante a melhor medida para a sua proteção e desenvolvimento. Valendo-se do método interpretativo lógico-finalístico da lei retromencionada, essa nova unidade familiar deve refletir um ambiente adequado à criança, levando-se em conta seu período formacional. Necessário, demais disso, não se olvidar das condições materiais e morais dos requerentes (PEREIRA, T., 1996), não significando, contudo, que será indeferido o pedido de adoção pelo singelo fato de os pretendentes serem financeiramente pobres.

\footnotetext{
4 "Toda criança ou adolescente tem direito a ser criado e educado no seio da sua família e, excepcionalmente, em família substituta, assegurada a convivência familiar e comunitária, em ambiente livre da presença de pessoas dependentes de substâncias entorpecentes." [grifo nosso]
} 
O papel desempenhado pela família substituta é o mesmo que a da natural. Ad hunc modum, consoante disciplina o artigo $227^{5}$ de nossa Lex maior, cabe a ela, juntamente com a sociedade e o Estado, assegurar, à criança e ao adolescente, o exercício de seus direitos fundamentais (PEREIRA, T., 1996).

Finalmente, diante da primazia irrestrita determinada pela Constituição no que se refere a fixar, entre os Diretos Fundamentais da criança, a convivência familiar, revela-se curial o incentivo à colocação do infante em família substituta quando por algum motivo tornar-se infactível a convivência junto de seu núcleo familiar original, devendo o abrigamento ser medida transitória, e não extensível para toda infância e adolescência como, pesarosamente, sói ocorrer.

\section{Aspectos éticos e jurídicos da adoção internacional}

A adoção por pais estrangeiros, disseminada como adoção internacional, é instituto jurídico de ordem pública, também vinculado ao direito privado, o qual concede à criança ou adolescente em estado de abandono a possibilidade de integrar uma família, ainda que em país distinto do que nasceu, desde que adimplidas certas condições dispostas em pactos entre os Estados envolvidos e na legislação interna do país do adotando. A Convenção de Haia ${ }^{6}$ de 29 de maio de 1993, atinente à matéria em destaque, reconhece que a prática da adoção internacional "pode apresentar a vantagem de dar uma família permanente à criança para quem não se possa encontrar uma família adequada em seu país de origem".

Matéria omissa em nossa legislação precedente, a adoção por pais estrangeiros é admitida na Constituição Brasileira em seu artigo 227, §5‥ ${ }^{7}$, havendo, ainda, remissão à mesma no artigo 1.629 do Código Civil. Contudo, é o Estatuto da Criança e do Adolescente que traz mais disposições sobre tal tema, sem fazer, ainda assim, maiores aprofundamentos.

\footnotetext{
5 “É dever da família, da sociedade e do Estado assegurar à criança e ao adolescente, com absoluta prioridade, o direito à vida, à saúde, à alimentação, à educação, ao lazer, à profissionalização, à cultura, à dignidade, ao respeito, à liberdade e à convivência familiar e comunitária, além de colocá-los a salvo de toda forma de negligência, discriminação, exploração, violência, crueldade e opressão". Nesse particular, observa-se que o Estatuto da Criança e do Adolescente foi elaborado seguindo as diretrizes deste dispositivo, reconhecendo o dever estatal de conferir integral proteção a todo e qualquer infante.

${ }^{6}$ A Convenção sub examine entrou em vigor internacional dia 10 de maio de 1995. Ratificada pelo Brasil, foi promulgada pelo decreto legislativo 3.087/99, passando a vigorar em território nacional a partir de 10 de julho de 1999.

7 "A adoção será assistida pelo Poder Público, na forma da lei, que estabelecerá casos e condições de sua efetivação por parte de estrangeiros."
}

Revista de Direito Púbuco, LondRINA, V. 3, N. 1, P. 30-42, JAN./ ABR. 2008. 
Prescreve 0 artigo $31^{8}$ do aventado estatuto que a colocação em família substituta estrangeira é medida excepcional, somente admissivel na modalidade de adoção. Pontua que deve haver estágio de convivência precedendo a adoção, o qual se fará apenas em território nacional e deverá ter um prazo mínimo de 15 dias para crianças de até 2 anos, e de 30 dias se 0 adotando contar com idade superior a essa ${ }^{9}$.

Requisitos ${ }^{10}$ precípuos para o deferimento do pedido são a habilitação no país de origem dos adotantes e estudo psicossocial elaborado no mesmo local. 0 §2ㅇ. do artigo 51 assenta como prerrogativa do magistrado determinar que os adotantes instruam o pleito com cópia da lei alienígena em vigência tratando acerca do tema, a fim de seja cotejada com a brasileira. Em que pese não ter sido previsto pelo legislador como cogente, deve o julgador valer-se dessa possibilidade em todos os casos, com vistas a não restar dúvidas no que respeita ao tratamento dado para a adoção no país primitivo dos adotantes.

A colação do texto legislativo estrangeiro tratando acerca da matéria é de suma importância, mormente já que, para o deferimento do pedido, faz-se mister observar se surtirão os mesmos efeitos no país dos adotantes, tais como, a título de exemplo, ser a adoção irrevogável e não gerar quaisquer espécies de distinções entre o filho natural e 0 adotado.

Devem ainda, os interessados, anexar declaração de ciência de que referida prática no Brasil é gratuita, não se olvidando que terão de atender, outrossim, aos demais requisitos exigidos para a adoção por brasileiros ${ }^{11}$. Todos os documentos trazidos aos autos deverão, necessariamente, ser traduzidos por profissional juramentado e autenticados pela autoridade consular. ${ }^{12}$

No que tange ao estrangeiro residente ou domiciliado no Brasil, considerando-se o princípio da isonomia, aliado ao ideal de não distinção, preceituados por nossa Lex Maior, aplicam-se àquele as normas relativas aos brasileiros, dispensando-se as condições que são exigidas para o estrangeiro com residência no exterior ${ }^{13}$.

\footnotetext{
${ }^{8}$ A colocação em família substituta estrangeira constitui medida excepcional, somente admissível na modalidade de adoção.

${ }^{9} \S 20$ do artigo 46 do Estatuto da Criança e do Adolescente.

${ }^{10}$ Constam os mesmos do artigo 51 do estatuto menorista.

${ }^{11}$ Exemplificativamente, juntada de certidão criminal negativa, comprovante de residência, cópia do holerite e de carteira de identidade, entre outros.

${ }^{12} \S 30$ do mesmo diploma legal.

${ }^{13}$ Nesse particular: TJRJ, 14ậâara Cível, rel. Elisabete Filizzola - j. 27.08.2001.
} 
0 instituto da adoção internacional tem caráter eminentemente humanitário, uma vez que torna possível a um infante desamparado ter um lar saudável e uma família. A excepcionalidade assinalada pela lei não deve servir de percalço para sua concretização. 0 escopo do legislador, ao criar inúmeros requisitos e declará-la exceção, foi buscar coibir práticas ilícitas e fraudulentas tão comuns no passado e que ainda hoje existem, tais quais o tráfico de menores. Ocorre, por seu turno, que inúmeros magistrados, via de regra, denegam requerimentos de adoção para casais estrangeiros, lastreando-se no aludido caráter extraordinário, porquanto ser a adoção internacional exceção à exceção ${ }^{14}$.

É fato que, em havendo tanto estrangeiro como brasileiro interessados em adotar uma criança, o último deve gozar de prevalência. 0 que se verifica na prática, ao revés, são nacionais buscando, na maioria das vezes, crianças recém-nascidas, havendo inclusive preferência por cor, permanecendo as crianças com idade mais avançada abandonadas em abrigos sem qualquer esperança de um dia serem adotadas por pais brasileiros. Em contrapartida, é cediço que os casais estrangeiros interessados em adotar, ordinariamente, não têm preferência por sexo, cor ou idade do infante, até porque há países em que a legislação comina diferença máxima de idade entre 0 adotado e 0 adotante. ${ }^{15}$

Nesse diapasão, pontifica Maria Helena Diniz (2007, p. 503) que:

seria mais conveniente [...] que se estabelecessem medidas eficazes para punir corruptos e traficantes, em vez de criar exigências para sua efetivação, visto que 0 estrangeiro está mais preparado psicológica e economicamente para assumir uma adoção, não fazendo discriminações atinentes à raça, ao sexo, à idade ou até mesmo à doença ou defeito físico que o menor possa ter; ao passo que o brasileiro é mais seletivo, pois, em regra, procura, para adotar, recém-nascido branco e sadio, surgindo, assim, em nosso país, problemas de rejeição social.

A eminente doutrinadora traz a baila a circunstância de que as adoções malintencionadas não devem afastar as feitas com o real fim de amparar a criança. Conclui indagando se não seria melhor prover às crianças o bem-estar material, moral, afetivo,

\footnotetext{
${ }^{14}$ Assim o é já que a adoção, por si só, é medida excepcional, de acordo com o que se conjuga do já comentado artigo 19 do Estatuto da Criança e do Adolescente: "toda criança ou adolescente tem direito a ser criado e educado no seio da sua família e, excepcionalmente, em família substituta [...]". Averbe-se a isso a redação do artigo 31 do mesmo diploma: "a colocação em família substituta estrangeira constitui medida excepcional [...]".

${ }^{15}$ Como na Itália, exempli gratia.
} 
dando-Ihes um teto acolhedor, ainda que no exterior, do que deixá-las vegetando nas ruas ou encerrá-las em locais de estabelecimento educacional (DINIZ, 2007).

Almejando a efetiva realização de nossa Constituição, que tem por fundamento a dignidade da pessoa humana, sendo regida em suas relações internacionais pelo princípio da prevalência dos direitos humanos, e que preconiza o direito da criança à uma infância sadia, devendo fazer parte de uma família, necessita o magistrado de extrema cautela antes de julgar improcedente um pedido de adoção por pais estrangeiros, muitas vezes dispostos a educar e dar carinho a infantes que se encontram relegados em abrigos, sem esperanças de ter um futuro digno.

A supracitada Convenção de Haia de maio de 1993, em seu artigo 1ํ., estabelece que os países signatários devem instituir medidas para garantir que as adoções por pais estrangeiros sejam realizadas primando pelo interesse superior da criança e com respeito a seus direitos fundamentais, assim como buscando prevenir a venda ou o tráfico de crianças.

Sobreleva destacar, outrossim, por oportuno, que o Estatuto da Criança e do Adolescente, em seus artigos 50 e 52, dispõe sobre a criação de organizações responsáveis pelo cadastro de pessoas interessadas em adoção, as nominadas Comissões Estaduais Judiciárias de Adoção - CEJAs, o que, em verdade, tornou-se corriqueiro em todo o território nacional. Tais organismos pertencem à Justiça Estadual e são de suma proeminência, notadamente no diz respeito à adoção internacional, pois possibilita a unificação de cadastros, tanto dos interessados, quanto das crianças disponíveis para adoção, tornando mais céleres os processos nesta seara.

Consoante já asseverado algures, a adoção internacional não deve ser atacada genericamente. Há que se verificá-la casuisticamente a fim de que se aufira se os interesses do menor serão protegidos e respeitados caso venham a ser adotados pela família interessada.

Não se deve perquirir a conveniência, ou não, de serem os infantes brasileiros adotados por estrangeiros residentes no exterior, "mas sim permitir seu ingresso numa família substituta, sem fazer quaisquer considerações à nacionalidade dos adotantes, buscando suporte legal no direito pátrio e no direito internacional [...]" (DINIZ, 2007, p. 503). Não é justo serem as crianças prejudicadas, perdendo a chance de integrarem um lar digno e profícuo, em decorrência de eventuais atitudes de organizações criminosas que, 
infelizmente, fazem-se presentes em qualquer sociedade. Essas sim devem ser combatidas pela Lei, não só brasileira, mas de todos os países, buscando a coibição de condutas repugnantes tais como o tráfico internacional de crianças.

De se destacar, ademais, a existência do tráfico interno de pessoas, dentro do território brasileiro, situação que, infelizmente, vem ocorrendo em larga escala, a qual é hábil a gerar implicações quase tão gravosas quanto as decorrentes do tráfico de menores para o exterior ${ }^{16}$.

Sobre a temática em tela, o juízo da célebre desembargadora Maria Berenice Dias (2007):

faz-se necessário revitalizar o instituto da adoção. Mas para isso urge agilizar o seu processamento, pois a injustificável demora subtrai a possibilidade de crianças maiores serem adotadas. Mister desmistificar as adoções internacionais, como se estivesse fazendo tráfico de crianças, ou pior, venda de seus órgãos.

Nesta senda, Maria Helena Diniz (2007, p. 509), faz menção à jurisprudência favorável à adoção internacional em caso de infante relegado por sua genitora há anos, sendo que, ainda que situação de caráter extraordinário, a modalidade de adoção in casu era medida que indubitavelmente viria em favor do adotand $0^{17}$. Ainda nesta mesma vereda:

ADOÇÃO INTERNACIONAL - Pressupostos - Excepcionalidade - Cabimento mesmo havendo casais nacionais - A releitura da norma menorista não conduz à interpretação de que o casal estrangeiro, que preenche os pressupostos legais deva ser arredado, invariavelmente quando existem pretendentes nacionais, principalmente quando já desenvolveram forte afeto ao menor, cujo interesse deve ser preservado. Casos isolados que abalaram o instituto de adocão internacional, não devem servir como escusa para frustrar o pedido, sendo injusto obstar que 0 infante desfrute de melhor qualidade de vida em país desenvolvido. Inteligência dos artigos 28, 31 e 198, VII do ECA. Apelação provida. Decisão unânime (Ap. Cível

${ }^{16}$ Registre-se ter sido necessária a criação pelo legislador no ano de 2005, através da Lei 11.106/2005, de um tipo penal específico (artigo 231-A do Código Penal) sob a rubrica "Tráfico Interno de Pessoas". Tal conduta consiste em "promover, intermediar ou facilitar, no território nacional, o recrutamento, o transporte, a transferência, 0 alojamento ou o acol himento da pessoa que venha exercer a prostituição", tendo como sanção prevista pena de reclusão, de 3 a 8 anos, e multa.

17 “Ementa da Redação: Embora se trate de medida excepcional, é cabível a adoção internacional de menor que há muito se encontrava em estado de abandono e institucionalizado, sem receber visitas de sua genitora que, não possui condições físicas e psicológicas para a criação daquele, agindo com omissão e negligência, mormente quando comprovado que os demais filhos também vivem em estado de desagregação familiar, à mercê de maus-tratos, abusos físicos e sexuais. Ap. 2003.001.29416 - Segredo de Justiça - 8a Câm. J. 18.12.2003 - rel. Desa. Odete Knaack de Souza - DORJ 03.06.2004" (DINIZ, 2007, p. 509). 
594039844 - 8a Câm. Cível - TJRS - J. 26.05.1994 - rel. Des. José Carlos Teixeira Giorgis). [grifo nosso $]^{18}$

Por fim, levando-se em conta as opiniões doutrinárias e arestos trazidos a baila, dessume-se que a adoção por pais estrangeiros é evento que não deve ser encarado como algo puramente prejudicial, devendo-se ponderar cada caso concreto de forma exclusiva. Atentar-se para as formalidades legais, aliando-se a isso a cooperação interestatal, pode ser saída crível para a situação em comento, qual seja, a adoção internacional.

\section{Conclusão}

Ante a pesquisa efetuada, em apertada síntese, pode-se concluir que a família é a pedra angular de toda e qualquer sociedade. Sua existência, datada desde os primórdios da humanidade, tem se mantido por todos os séculos, adequando-se, tal instituto, às transformações decorrentes da sociedade hodierna.

Com a evolução dos tempos, percebeu-se a necessidade de leis que, além de proteger a família como um todo, tivessem por escopo proteger a criança e 0 adolescente, seguindo o princípio do respeito à dignidade da pessoa humana, o qual norteia nosso ordenamento jurídico bem como a instituição familiar. Uma das formas de se efetivar na prática a aludida proteção à infância revela-se por meio da adoção.

Com 0 advento da Constituição Federal de 1988 e a promulgação do Estatuto da Criança e do Adolescente em 1990, proporcionou-se às crianças e adolescentes de nosso país uma proteção merecida, instituindo-se a doutrina da proteção integral e arrolando-se as garantias conferidas aos infantes.

Em que pese a existência de tais garantias, muitas vezes não se vê na prática sua aplicação, divergindo-se então do que pregam nossas leis. Forçoso se faz que as regras contidas em nossos diplomas legais sejam efetivamente cumpridas, para que se possa haver justiça e igualdade na vida das crianças que se encontram em situação de desamparo, possibilitando a sua inserção em família substituta.

\footnotetext{
${ }^{18}$ Também favorável à adoção internacional, o seguinte acórdão proferido pelo Egrégio Tribunal de Justiça do Estado do Rio de Janeiro: "ADOÇÃO - CASAL ESTRANGEIRO - Preenchimento de todos os requisitos exigi dos por lei para o procedimento - Admissibilidade - Fato de ser dada preferência a casal brasileiro não pode prevalecer em situações que tragam maiores vantagens para o adotado em obter uma vida melhor" (Apel./Proc. N. 635/96 - TJRJ - Rel. Des. Paulo Sérgio Fabião - DORJ 04.06.1998).
} 
No que tange à adoção internacional, ainda que seja por muitos combatida, sob argumentos como o de favorecer o tráfico internacional de crianças, ou ainda a exploração da prostituição infantil em outros países, deve-se considerar os benefícios que podem decorrer de tal espécie de adoção, não se fundamentando unicamente nos aspectos negativos que podem ser atingidos através daquela por pessoas de má fé.

Ressalte-se que, como em todo instituto jurídico, sempre existirá a possibilidade de desvio de finalidade, mormente através de fraudes, e, assim como em qualquer campo do Direito, tal fato não retira suas reais conveniências, competindo ao ordenamento jurídico criar mecanismos hábeis a coibir seu uso de forma errônea e desvirtuada.

Não deve ser a adoção internacional discriminada, sob pena de se criar um nacionalismo preconceituoso e prejudicial ao desenvolvimento de nosso país. Conforme já pontuado, não se pode descurar das observâncias imanentes ao instituto, cabendo ao Poder Público efetuar todo o controle necessário para que não haja distorções do que reza o texto legal.

Por derradeiro, deve-se ter em vista o já salientado caráter humanitário da adoção, uma vez que a mesma pode possibilitar que crianças e adolescentes, sem quaisquer esperanças de um futuro promissor, pertençam a um lar e integrem uma família, transmutando, de forma inconteste, a realidade de tantos infantes abandonados em abrigos, quando não nas ruas, que assola nosso país há décadas. Daí a existência de vertente favorável inclusive à adoção por pares homossexuais, a qual vem ganhando força considerável nas últimas décadas, alicerçada no direito constitucionalmente assegurado e conferido às crianças de que essas pertençam a uma família.

\section{Referências}

ALBERGARIA, Jason. Adoção plena. Belo Horizonte: Del Rey, 1996.

ARAÚJO, Luiz Alberto David; NUNES JÚNIOR, Vidal Serrano. Curso de Direito Constitucional. 2. ed. São Paulo: Saraiva, 1999.

CHAVES, Antônio. Adoção, adoção simples, adoção plena. 2. ed. São Paulo: Revista dos Tribunais, 1980.

COSTA, Tarcísio J. M artins. Adoção transnacional: um estudo sociojurídico comparativo da legislação atual. Belo Horizonte: Del Rey, 1998. 
CURY, M unir et al. Estatuto da criança e do adolescente anotado. São Paulo: Revista dos Tribunais, 1991.

DIAS, M aria Berenice. Paz para a Infância do M undo. Disponível em: বttp:// www.mariaberenicedias.com.br>. Acesso em: 15 out. 2007.

DINIZ, M aria Helena. Curso de direito civil brasileiro: direito de família. 22. ed. São Paulo: Saraiva, 2007. v. 5.

FELIPE, J. Franklin Alves. Adoção, guarda, investigação de paternidade e concubinato. 4. ed. Rio de janeiro: Forense, 1993.

FERREIRA, Pinto. Curso de direito constitucional. 5. ed. São Paulo: Saraiva, 1991.

FERREIRA FILHO, M anoel Gonçalves. Curso de direito constitucional. 17. ed. São Paulo: Saraiva, 1989.

GOM ES, Orlando. Direito de família. 3. ed. Rio de Janeiro: Forense, 1978.

LÔBO, Paulo Luiz Netto. In: AZEVEDO, Álvaro Villaça. (Coord.). Código civil comentado. São Paulo: Atlas, 2003. v. 16.

MIRANDA, Pontes de. Tratado de direito privado. 4. ed. São Paulo: Revista dos Tribunais, 1983. v. 9.

OLIVEIRA, J. M. Leoni Lopes de. Guarda, tutela e adoção. Rio de Janeiro: Lumen Juris, 1997.

OLIVEIRA, José Sebastião de. Fundamentos constitucionais do direito de família. São Paulo: Revista dos Tribunais, 2002.

PEREIRA, Caio Mário de Silva. Instituições de Direito Civil: direito de família. 14. ed. Rio de Janeiro: Forense, 2004. v. 5.

PEREIRA, Tânia da Silva. Direito de Família e o Novo Código Civil. 2.ed. Belo Horizonte: Del Rey, 2002.

. Direito da criança e do adolescente: uma proposta interdisciplinar. Rio de Janeiro: Renovar, 1996.

RODRIGUES, Silvio. In: CURY, M unir. (Coord.). Estatuto da criança e do adolescente comentado: comentários jurídicos e sociais. 7. ed. São Paulo: Malheiros, 2005.

SANSEVERINO, Ana Lúcia M utti de Oliveira. O estatuto da criança e do adolescente: a adoção na nova lei. Revista Justitia, São Paulo, v. 153, jan./mar. 1991. 
SILVA, José Afonso da. Curso de direito constitucional positivo. 15. ed. São Paulo: Malheiros, 1998.

SILVA, José Luiz M ônaco da. A família substituta no Estatuto da Criança e do Adolescente. São Paulo: Saraiva, 1995.

SIQUEIRA, Liborni. Adoção no tempo e no espaço: doutrina e jurisprudência. 2. ed. Rio de Janeiro: Forense, 1993.

SZNICK, Valdir. Adoção. 3. ed. São Paulo: LEUD, 1999.

VENOSA, Sílvio de Salvo. Direito civil: direito de família. 3. ed. São Paulo: Atlas, 2003.

WALD, Arnoldo. 0 novo direito de família. 12. ed. São Paulo: Revista dos Tribunais, 1999.

WEBER, Lídia Natalia Dobrianskyj. Da institucionalização à adoção: um caminho possível. Revista Igualdade, n. 09, dez. 1995. 